\title{
Food shopping and weight concern. Balancing consumer and body normality
}

Nielsen, Annemette Ljungdalh; Holm, Lotte

Published in:

Appetite

DOI:

10.1016/j.appet.2014.07.024

Publication date:

2014

Document version

Peer reviewed version

Citation for published version (APA):

Nielsen, A. L., \& Holm, L. (2014). Food shopping and weight concern. Balancing consumer and body normality. Appetite, 82, 213-220. https://doi.org/10.1016/j.appet.2014.07.024 


\section{Food Shopping and Weight Concern: Balancing Consumer and Body Normality}

\section{Published in:}

Appetite

DOI:

dx.doi.org/10.1016/j.appet.2014.07.024

Publication date:

2014

Document Version:

Accepted manuscript

Citation for published version (Harvard):

Nielsen, A \& Holm, L 2014, 'Food shopping and weight concern. Balancing consumer and body normality' Appetite, vol 82, s. 213-220. 


\section{Title: Food Shopping and Weight Concern: Balancing Consumer and Body}

\section{Normality}

Authors: Annemette Nielsen, Department of Food and Resource Economics and Department of Nutrition, Exercise and Sports, University of Copenhagen, Rolighedsvej 25, DK-1958

Frederiksberg C, Denmark.

Lotte Holm, Department of Food and Resource Economics, University of Copenhagen, Rolighedsvej 25, DK-1958 Frederiksberg C, Denmark. loho@ifro.ku.dk

Corresponding author

Annemette Nielsen, Department of Food and Resource Economics, University of Copenhagen,

Rolighedsvej 25, DK-1958 Frederiksberg C, Denmark.

Tel: +45 3533 2621, e-mail: anmn@ifro.ku.dk

Sources of support

The study was financed by the Danish Research Agency's programme for food and nutrition research (FELFO/2056-03-0016). 


\begin{abstract}
The desire to achieve a normal, culturally acceptable body is often seen as the main driver of foodconsumption practices adopted by individuals who are concerned about their body weight. In social research into weight management self-control is therefore often a central theme. Turning the focus towards practices and values related to food shopping, this study adds to our understanding of central features in perceptions of normality among people with weight concerns. In a qualitative study 25 people who participated in a dietary intervention trial in Denmark were interviewed and five people were observed. The study shows that the aim of achieving a normal body does not eclipse the importance of enacting values linked to ideas of the 'normal consumer'. Using empirical examples, the study illuminates how consumer freedom is attained in ways that are both complementary to, and in conflict with, practices and experiences of controlling food intake. The paper suggests that freedom and control are composite and complementary ideals of normality for people with weight concerns. On the basis of this insight, the authors discuss the contribution the paper makes to existing studies of weight management and food consumption.
\end{abstract}

Key words: control of food intake; normality; consumer behaviour; qualitative methods; food sociology 


\section{Introduction}

Obesity is viewed as a deviant condition, both in science and in daily life. Much effort is invested in remedying this condition by turning deviant bodies into 'normal' bodies. The concept of 'normal' has been described as "the most powerful ideological tool of the twentieth century" (Hacking 1990: 169) as it functions to link 'is' with 'ought'. Representations of what is 'the normal' combine descriptions of the typical, or the ordinary, with normative views of the 'right' and 'good'. Such representations often set the terms for political and scientific, as well as lay, understandings.

In this paper we explore how values of freedom and control are involved in defining normality in a group of young people with weight concerns. The aim is to contribute to a more nuanced understanding of the way in which people with weight concerns operate in the world, and define themselves. We do so through an investigation of how values related to being 'normal' are involved in the perceptions and practices connected to supermarket shopping. By situating our study in the field of consumption we focus on an arena in which the individual's experience of freedom is central. We thereby bring out the value of freedom in the research field of obesity, which has been very focused on exploring the value of self-control.

\section{Obesity, control and freedom}

Much social scientific research on obesity and overweight suggests that social stigmatisation and cultural categories of deviance and normality are all-dominant influences on the practices and understanding of eating among overweight and obese individuals, who want to lose weight (Germov \& Williams, 1999; Lupton, 1998;Sobal, 2004; Stearns, 1997; Stinson, 2003; Lewis et al., 2011). In these studies, the concept of self-control is highlighted as central to the understanding of the strategies which such individuals apply to deal with their bodyweight. In addition, self-control is 
described as a core value applied in these individuals' judgement of their own and others' capacity to attain the goal of a normal body (Stinson, 2003). The centrality of the concept is underlined in their descriptions of themselves and others with heavy bodies as lazy, morally weak or undisciplined, characteristics which reflect perceptions of fat bodies in society at large (Lewis et al., 2011; Hopkins, 2012). To achieve self-control is thus often presented as the all-dominant concern of people with weight concerns (Sobal, 2004; Yuker \& Allison, 1994; Robertson et al, 2014; Hopkins 2012).

On the other hand, studies of resistance to dieting and to the dominant narrative of obesity point to concepts other than self-control as central to the analysis of weight concerns. They do so by illuminating the more complex definitions of health and body size that lie behind such resistance (Chapman 1999; Cordell \& Ronai 1999). These studies show that even though the achievement of a so-called normal body is a central goal, the definition of normality includes other parameters that are seen to involve freedom or release from self-control. Such parameters include social participation and psychological well-being.

In this paper we analyse the way in which values of freedom and control interact with, and are embedded in, the food shopping practices of people with weight concerns. Studies of the way overweight or obese individuals approach food shopping have been conducted in the course of psychological and behavioural experiments on, for example, the impact on food purchasing of social network, health information, and weight management reminders (Bevelander et al. 2011; Saarela, 2013; Papies et al. 2014; Au et al. 2013). Studies of the experience of living in a large body, and of body weight stigmatization, have also dealt with contexts of consumption. These studies have focused on situations involving public exposure of either the body or the activity of 
eating, such as restaurant dining or shopping for clothes (Christiansen et al. 2012; Lewis et al. 2011; Hopkins, 2012).

Hopkins (2012) has applied the concept of intersectionality in order to direct attention to ways in which the experience of being obese or overweight is shaped not only by body size, but by other identities related to, for example, gender, ethnicity, class, sexuality and age. So far, however, little research has been conducted on the way people with weight concerns experience themselves as consumers in the context of food shopping, and on how this shape their practices and experiences. This is surprising, since consumption is often taken to be central to late modern identity formation (Beck 1992; Giddens 1991; Bauman 2007), and since several authors have reported how obese and overweight people feel stigmatized in the context of food shopping (Thomas et al. 2008; Lewis et al.2011). By putting the focus on the context of shopping, two aspects of obtaining a normal identity move to the forefront. These two aspects are the attempt to achieve or maintain a normal body and the attempt to practice what is seen as normal consumption.

In this study we explore how values of freedom and control are involved in strategies to obtain normality among a group of "people with weight concerns". We refer to our informants in this manner, because at the time of our study not all participants were 'overweight' or 'obese' by medical standards due to their parallel participation in a dietary trial (see details below). The study builds on data obtained from observations of food shopping events and from interviews about shopping. However, before these data are presented, the theoretical framework for the analysis needs to be established. It is within this framework that we shall explore how the values of freedom and control relate to understandings of 'normal' consumption and, in particular, how they relate to the act of food shopping. 


\section{Freedom and control as strong, interacting cultural values}

In his essay on discursive framings of health, Robert Crawford (1984) points to the conflicting cultural values of self-control and release. In interviews with people about health, he identifies a tendency amongst some to define a good lifestyle as the promotion of healthy living in terms of discipline and self-control. Others in contrast emphasise living life to the full including not allowing authoritative voices on health to reduce the pleasures of life such as the joy of eating. Crawford suggests that the root of these conflicting dimensions of health is to be found at a material level, in the basic constituents of capitalist society. Here, the need for the disciplined production of goods contrasts the need for non-restricted consumption of the same goods.

In contrast to Crawford's work, Rose (1996) does not view the values of freedom and selfcontrol as contradictory. He identifies the root for the instalment of these values in individual's selfperception, experience and practice in the formation of liberal societies. Here freedom is the central technique of governance. In earlier phases of liberalism, individual freedom was sanctioned by public authorities and closely connected with the exercise of civility, orderliness and rationality. The readiness to become educated, for instance, in matters of hygiene and health, was fundamental to the perception of individual liberty.

In liberalism's present phase, the authorities, which previously controlled life through direct force and strict traditions, have largely lost their power. Now the enactment of freedom is, Rose claims, closely dependent on consumption. Through consumption the individual is expected to be able to 'establish an identity through shaping a meaningful everyday life' (Rose, 1996: 17). Stressing the ambivalent character of the value of freedom, Rose points out that in a consumptionbased society, the individual is not only free to choose, but obliged to do so.

In the writings of Crawford, Rose and others (Bauman, 2003; Bauman, 1992; Giddens, 1991; Taylor, 2003), control and freedom are values in past and present liberal societies which relate to 
each other in the lives of individuals in both conflicting and complementary ways. Control from a source outside the individual - in the shape of formal authorities, systemic structures or social norms, is a precondition for individual liberties to unfold. For instance the liberty to pick and choose and to touch products in the supermarket depends upon the existence of social norms and social control mechanisms which sanctions the destruction or theft of such products. As will be clear from the case analysed in this article, when bodies, food desires and eating behaviours exceed existing norms, control from outside may be experienced as both positive and negative in relation to the freedoms associated with shopping. Likewise, the exercise of self-control may be experienced as freedom because of the lack of external control, or it may be experienced as control because of the deliberate renunciation of some freedom in order to fit into authoritatively or socially sanctioned norms.

Concepts of norm and normality are thus closely tied to the individual's experience of freedom and control. Such concepts function as measures against which individuals may judge their own actions and those of others, indicating when freedom and control are exercised in acceptable or unacceptable ways.

\section{Freedom and control as constituents in consumption}

In line with the arguments of Crawford and Rose, several authors have suggested that in liberal and capitalist societies the consumption of goods is primary to the enactment and understanding of the individual's experience of freedom. But freedom enacted through consumption, they stress, involves discipline, self-restriction and both social and structural control (Baudrillard, 1998; Bauman, 1992; Giddens, 1991; Slater, 1996; Falk \& Campbell 1997; Featherstone 2007). 
Balancing the relationship between values of freedom and control in modern consumption has been conceptualised in terms of tamed or calculated hedonism (Sassatelli $2001 \&$ 2009; Featherstone 2007). The ability to "loosen the control on aesthetic and emotional experiences" (Featherstone: 58) and promote desires and pleasures while still controlling them constitutes a dominant norm. In this way, freedom is defined in terms of giving in to emotional impulses. Lehtonen and Mäenpää (1997) have noted how in consumption the expression of freedom is not only tied to the actual act of purchase but just as much to the sensory acts of seeing, feeling, testing out, tasting, and smelling products and product displays. They claim that such aspects of shopping have moved to the foreground of the individual's shopping experience. Parallel to this, Campbell (1996) has argued that pleasure related to shopping always arises out of stimulation from material products which provide the substance from which the consumer constructs his or her own private daydreams of pleasurable experiences. However, Miller's detailed empirical study of shopping practices in north London (Miller, 1998) leads him to suggest that in modern consumption, hedonism is first and foremost an important value at a discursive level. At the level of the actual act of shopping it is thrift that constitutes the 'the normative ethos' (Miller, 1998: 48).

\section{Structural vehicles behind consumption practices}

But consumption and the act of shopping are not only about consumers' attributed meaning. They are also constructed by forces beyond the control of consumers. Though guided by consumer demands it is the retailers who decide what is to be placed on the supermarket shelves, when, and at what price. Further, supermarkets and malls are arenas where the behaviour of consumers is strategically influenced by architects and planners aiming at disturbing the consumer's rational planning of the shopping trip and luring them into impulse purchases (Bowlby 1997; Lave 1988). The principle of self-service, for example, simultaneously contributes to the image of rationality in 
planned shopping and ensures customer pleasure by providing direct access to the product, including the ability to explore, look and touch freely (Bowlby 1997).

The analyses of consumption presented above highlight that values of freedom and control are strong social and cultural norms in consumption and in the act of shopping. They further highlight, that these norms are closely linked to the materiality of products and venues, in which shopping takes place. This is an important framework for analysing how food shopping is performed by people with weight concerns; a topic to which we soon turn.

\section{Study design}

The act of shopping and the values related to this act were studied using interviews and observations of shopping practices. Data covered the physical presence in the supermarket, the prior planning of the purchase and the handling of goods afterwards. Observations and interviews addressed shopping in ordinary supermarkets and in a supermarket built especially for the purpose of a scientific intervention project in which our informants took part. All observations and interviews were carried out by the first author of this article.

\section{The study population}

The people who served as informants in the study were all participants in a long-term dietary intervention study, Mono Unsaturated Fatty Acids in Obesity (the MUFObes study from 2004 to 2008) which investigated the effect of two different diets on weight loss maintenance (Due et al. 2008). All 127 participants in the MUFObes study were healthy, individuals, aged between 16-35 years who had volunteered for trial participation in response to public advertisements. They were all defined as medically obese or overweight according to World Health Organization standards and 
had not gained or lost more than $3 \mathrm{~kg}$ of body weight within two months prior to the intervention study. Candidates were not recruited if they smoked, were pregnant or were breast feeding. Participants were required to lose a minimum of $8 \%$ of their body weight on a supplement-based low-energy diet (Nutrillett, Dansk Droge, Ishøj, Denmark) prior to participating in the study. After the weight-loss period, they were randomly assigned to one of three different types of diet for an eighteen month weight-loss maintenance period: the MUFA diet was composed in accordance with the recommendations of the American epidemiologist Walter Willett (2001), the NNA diet was composed in accordance with Nordic nutritional recommendations and the Control diet corresponded to the average diet of the Danish population.

Food provisioning during the intervention took place in two distinctly different settings. During the first 6 months of the intervention, participants were required to pick up all the food they consumed from a special supermarket built for them at the Department of Human Nutrition at the University of Copenhagen. All food collected was registered by the study staff, who via a special barcode system ensured that the composition of macronutrients was in accordance with the requirements of the diet each participant was assigned to (Due 2008). In addition, participants received counselling from a dietician. At the product level, participants were free to choose from the available selection of foods. For most products this was done on a choose-and-weigh-it-yourself basis, and there was no restriction on the amount of food they could bring home. All food was free of charge. During the next 12 months, participants went back to shopping in ordinary supermarkets and grocery stores at their own expense. None of the trial diets required the intake of products which would not be available in an ordinary supermarket. 
Participants all lived in the Greater Copenhagen area and shared a common interest in maintaining their achieved weight loss. Together they represented a broad variety of social backgrounds in terms of education, employment, marital status and income.

\section{Interviews}

In our study, 25 participants, ten participants from each of the NNA and MUFA groups and five from the Control group, were interviewed twice, six months apart. Participants were contacted first by letter informing them briefly about the aim of the sociological study and about our interest in recruiting them for this study. It was stressed that participation was voluntary and not a part of their obligation to the intervention trial. Then participants were telephoned by the first author in order to know their response to the letter and in order to reply to any queries. In all, 13 women and 12 men were recruited. Of these, 16 lived alone and 9 lived in households where they ate with others on a regular basis. An almost equal distribution was obtained between informants who were students (11) and employed (14).

The first set of interviews was conducted when a few of the informants had just started the second period of the MUFObes study and others were at the end of the first. The second set of interviews took place half a year later. Interviews were qualitative and semi-structured and based on an interview guide, which included an evaluation of the diet type informants followed in the MUFObes study, and a description and evaluation of changes in eating, shopping and cooking practices during their participation in the intervention. Inspired by data obtained through observations, the second set of interviews had a special focus on the theme of shopping. To verify data, and to encourage informants to introduce their own topics and themes, all interviewees were offered the opportunity to read the transcript from their first interview session and to comment in 
connection with the second interview. The interviews lasted between 30 minutes and 2 hours, and were tape-recorded.

\section{Observation}

Five MUFObes participants were followed on two or three shopping occasions each, resulting in the observation of 12 shopping events. The informants were recruited in connection with the first set of interviews. They included two participants from each of the NNA and MUFA groups and one from the Control group, two women and three men. Two informants were students and three were employed. Only one informant lived in a shared household, with his girlfriend. For the sake of the readability of this account, the five informants from the observation study are here provided with fictitious names: Laura, Bryan, Thomas, Kirsten and Peter.

All observations covered shopping trips lasting between 10 and 35 minutes, with an average of 20 minutes. Observations in all but one case also included the trip to and from the informant's home. This made more-detailed interviews possible. The place of shopping was in each case chosen exclusively by the informant, and all trips except one were to a supermarket. On all occasions, the informant was asked to 'think aloud' as much as possible while conducting the shopping. In addition, questions would be asked along the way. Inspired by Spradley (1980), an explorative observation matrix was designed by the authors in order to cover relevant themes in participants' shopping practices. This guide covered five predefined dimensions: Place, Products, Actors, Time and Context, which were explored and partly interlinked through a set of sub-questions. Examples of these are: Place: Where does shopping take place/ not take place? What connections does the shopper make between the shop and specific food products? How do different actors influence the choice of shopping place? How does time influence choice of shopping place? What other criteria 
influence selection of the shopping location? How are different shopping locations described and evaluated?

Written notes were used to record the shopping events, and detailed notes were made within 15 minutes of leaving the informant.

\section{Data analysis and developing of codes}

All interviews were transcribed ad verbatim and transcripts were coded repetitively using the software Atlas.ti. Coding procedures followed inductive and deductive principles (Strauss \& Corbain 1998) and initially consisted of a thematic organising of data in accordance with the research questions operationalised in the interview guide. In a second round of coding, a more inductive approach was followed. A third round of data treatment consisted of comparing codes from interview analysis with those generated in the reading of observational data. During this process, the analytical focus on the values of self-control and freedom was developed.

In the analysis procedure, the code which referred to informants' descriptions of values of control was assigned to informants' use of terms such as 'surveillance', 'watching over', 'self-discipline', 'character strength' and 'obligations'. Terms such as 'desire', 'spontaneity', 'choice', 'breaking rules' (of intervention trial), and 'committing sins', were coded and interpreted as expressions of 'freedom'. In accordance with qualitative methodology (Alasuutari 1995), we assigned codes related to norms and normality to direct references to concepts of normality (e.g. 'ordinary', 'usual', etc.) and to indirect concepts expressing deviance from the norm, failure and matters out of the ordinary. 


\section{Results}

The comparison between the artificial shopping arena of the intervention trial and ordinary food shopping arenas made specific values of shopping explicit which may otherwise have been too tacit and self-evident to be mentioned in interviews and informal conversation. These values related to participants' perceptions of consumer normality. However, only rarely would participants use the word 'normal' to evaluate their shopping behaviours or experiences. Rather, they would implicitly state their concepts of normality in talk about what they saw as examples of their own deviance from the norm - such as, for example, 'failure' or 'lack' of certain competences when shopping for food; in their stressing of certain conditions in the trial supermarket as unusual in comparison to the way they would shop in ordinary supermarkets; and in their descriptions of the emotional effects, for example, frustration, boredom or relief that these special conditions set off. Ideas of normality would also be expressed in the self-evident and unreflective manner in which certain shopping practices, such as being attentive to and choosing a good bargain even if the product was not on the shopping list, were carried out.

In the following, we shall first focus on how the values of, respectively, control and freedom were expressed in participants' food shopping practices - both when shopping at the trial supermarket and when shopping in 'real life'. We shall then end the section by describing in more detail, how, in order to achieve bodily and consumer normality, the two values were balanced against each other in the context of 'real life' food shopping.

\section{Body normality and values of control in food shopping}

The controlled design of the MUFObes study was conceived by participants as a major asset in terms of giving them a unique chance to achieve and maintain a body weight within the 'normal' range as defined by WHO. Participants would describe themselves as lacking discipline, will power 
or character strength, or as possessing a 'weak backbone', when explaining that they needed someone else to help control their food consumption. The strict control exerted by the study staff, in a very direct sense, hindered participants in purchasing some of the foods they would normally eat. But the first period of the trial, where participants were submitted to this external control, was also a process of socialisation where they learned self-control as explained by a grateful participant:

In the MUFObes store, I have learned to shop, and to think and shop in terms of breakfast, lunch and dinner (...). I have become better at this and I no longer just blindly grab things from the shelves or buy what I think would be nice to have, right there and then. (Male informant)

In the interviews, informants reported the new shopping practices they had learned during the intervention. They stressed the efforts they had made to plan the purchase and to limit their shopping frequency to once or twice a week. Observations showed examples of how new competences of control were employed when shopping in ordinary supermarkets after the first trial period. Some informants brought shopping lists, and they studied the nutritional labelling on most products they considered buying.

Participants also engaged in efforts to block or change sensuous stimulations which they considered risky and which would lead them towards unwanted products and practices. Some referred to drinking water or sugar free sodas, eating raisins or smoking before entering the supermarket as efficient means of minimising the risk of such temptations. Some participants reported how they engaged in inner dialogues when they felt tempted to buy something:

The brain goes: "I want that now". And then I have to convince it: "well, it is not really necessary. Let us just go home, and then we will wait until the weekend comes." (Male informant) 
In general, participants regarded deliberate reflection and consciousness about their ways of eating as important in achieving, or maintaining, weight loss. But other competences were functional too. From the observational data it appeared, that informants' familiarity with the structure of the supermarket could be used to dispel the tempting magic of foods. Kirsten rushed through the supermarket in great haste. Her familiarity with the layout of the supermarket enabled her to focus exclusively on products for the one meal she had planned to prepare. She claimed this was her usual shopping practice. Some informants explicitly designated certain parts of the supermarket as 'forbidden territory' and avoided them in order to avoid temptation. Peter for instance would stand passively in the section with paper towels and toilet paper, waiting for his girlfriend to collect some of the goods which involved passing by the selves with chocolate and crisps.

While being crucial for maintaining weight loss, control was, however, in some cases a barrier to bodily normality. Ordinary supermarkets exercised types of control that conflicted with the participants' wish to regain, or retain, normal body size. In real-life shopping, it was not considered possible/practical to calculate one's needs on a meal-by-meal basis, as most goods are simply not sold on a choose-and-weigh-it-yourself basis. This was a cause for considerable worry and frustration for several of the people interviewed. The following observation is typical:

Laura grabs a bag of walnuts and explains to me that half of it is for snold [i.e. candy] this week and half is for next week. She explains that being "forced" to buy such a large portion [the bag is one of $150 \mathrm{~g}$.] leads her to eat more. She gives an example from last weekend, where she had bought candy for her friends who were visiting. Normally, on Mondays, when getting home from work she would just eat an avocado for supper [as Mondays are her long days at work, where she eats dinner at the workplace]. But because there was still some candy left over from the weekend, she ended up eating both the avocado and the candy. (Field notes) 
In this case, external control, in the form of portion size, is experienced as influencing shopping practices in unwanted directions, not as supporting efforts of self-control. In parallel, some regarded buying products at reduced prices almost a consumer obligation regardless of whether it conflicted with the goal of reducing temptations to eat more. Participants' solutions to such conflicts included establishing specific control strategies at home, for example, by storing products away or splitting the large but cheap portions they brought home into smaller ones.

Participants' reflections and practices related to the value of control indicate that, in the context of shopping, both external and internal forces of control are experienced as pivotal to success in obtaining or retaining a desired body weight. However, we shall now turn our focus towards another matter of importance, that of exercising freedom.

\section{Consumer normality and values of freedom in food shopping}

When informants discussed the experience of shopping in the trial supermarket, ideas of normal consumption practices that were linked to the value of freedom were often explicated:

They [the trial staff] also tell us to try and act as normal as possible; that we should remember to get the good stuff too. (...) That we also need a little cosiness - for instance, a little chocolate and things like that;(...) because it is not supposed to be BORING all the time. One would also eat chocolate or crisps during weekends or whenever under NORMAL circumstances. And I had to get used to that. That it was actually OKAY to bring some chocolate home or to grab some crisps. I mean, that they do not look at you in a FUNNY way if you do it, as if they think: "What is she doing? If she had not picked that bag of chips, maybe her weight would have stayed where it was supposed to be (small laugh). (Female informant) 
This example illustrates how shopping at the trial supermarket made the participants feel acknowledged as normal consumers. The informant experiences the norms of the staff to be similar to her own regarding the purchase of weekend goodies and regarding the release from everyday life rhythms which the purchase of such goods represents in 'normal' life. In line with many others, this informant also expressed relief not to be confronted with moral judgement in the trial supermarket and the way in which this lessened her feeling of deviance.

Other informants expressed the same feeling of normality in relation to trialsupermarket shopping, when they contrasted these experiences with other weight loss programmes:

Eating like this fits much better to life in an ordinary family. (...).It has to do with the fact that one is not put under pressure to eat in any particular way. It does not HAVE to be $300 \mathrm{~g}$ of vegetables. So I mean it is more up to you how many vegetables you eat. (Female informant)

Compared to other weight-loss programmes, the MUFObes study is considered to accord better with the ambition of living a normal and autonomous life. It provides informants with greater freedom of choice regarding what to buy and eat, and limits boring and monotonous eating.

In the examples above, the trial supermarket supported participants' feeling of being able to act as normal consumers. It enabled them to make choices based on immediate desires within a controlled framework. Such choices were not linked to 'worry' and 'guilt', and in this way the trial helped them obtain a situation of desired normality in which food is defined in relation to both necessity and pleasure. The design of the MUFObes study was hence valued by participants, not only as a means of restraining them from certain desires, but also of freeing them from restraints.

However, the external control of the trial supermarket in some cases also acted as a barrier to consumer freedom. Some informants stressed that the trial supermarket, in comparison with real-life 
shopping, limited their ability to act as consumers in the way they wanted. These informants typically described how at the outset of the project they were thrilled when they went shopping due to the free-of-charge purchase opportunity and the newness of the situation. But, during the course of the trial, the excitement gradually faded. Some became tired of registering everything they got and of not being able to plan their food purchases for more than one week at a time. Some became bored with the trial supermarket. They longed to shop again among a wider selection of products in a bigger supermarket, where they could find new products along with well-known brands which they missed:

I always enjoyed having three different kinds of mustard or some strange kinds of gravies - for instance, fish sauce and things like that - in my cupboards (...). So in this way I have felt a bit restrained by the trial, because sometimes when you stand in a supermarket, where they have crazy amounts of this stuff you just go: "I would like that one and that one and that one and that one (gasps)!" And then you go: "But, well, I'd better not" (laughs). (...) I don't want to restrain myself in that way." (Female informant)

Feeling free or unrestrained in one's shopping, according to informants, entailed having a large variety of products to choose from in various food categories. It also entailed the possibility of choosing the location and time for shopping.

\section{Achieving consumer normality in a situation of weight concern - Balancing freedom}

\section{and control}


Observations of shopping practices in ordinary supermarkets showed how values and norms of consumption influenced informants' purchases of food, and how, in different ways, informants managed to balance such values and norms against values related to weight control.

Often, choosing a food product because it was the cheaper choice appeared so natural and self-evident that the choice was not even reflected upon in terms of weight-loss ambitions. This can be seen in the case of Thomas, in the extract given below. Thomas belonged to the MUFA group and was required to limit his intake of dairy fat, but he did not evaluate his choice of cheese in relation to this:

We go to the refrigerators with crème cheese. I ask Thomas what he is going to use the cheese for, and he tells me that he uses it for casserole dishes and as spread on bread. One kind of cheese is on offer - two packages for a cheaper price. Thomas explains to me that he chooses this kind of cheese because of the offer rather than the one next to it which is a low-fat variety. His total saving is 3 Dk.kr [half a Euro) compared to the low-fat product. (Field notes)

As pointed out above, saving money was almost regarded as an obligation, even if it was also a cause of frustration to some informants because it worked against weight-oriented strategies for self-control. But observations showed that the value of thrift was also employed by informants as a welcome opportunity to legitimise pleasure in shopping situations. Laura and Bryan both mentioned the 'spot market' as their favourite place in the supermarket. In some discount supermarkets, this is a section devoted to special bargains on all sorts of products. At the spot market, products that do not belong to the standard range of products in the supermarket lie in an apparently random mixture: clothes among electrical equipment among food products. Here shopping lists simply lost their relevance, and it seemed fully legitimate to let oneself be tempted to respond to an irresistible offer. In this way the codex of saving money creates a legitimate opportunity for Laura and Bryan 
to expose themselves to the risk of being seduced by products they would otherwise try to avoid through various strategies of self-control.

Observations showed how, during the course of shopping, informants were able to create several such opportunities for fulfilling norms of consumption related to spontaneous action, the fulfilment of personal desires and the search for novelty.

Another observation also illustrates the creation and exploitation of a choice option, this time with Kirsten. Kirsten belonged to the NNA group and was therefore allowed to eat carbohydrates in the form of white bread, but she had no plans to buy any during this shopping trip:

It is $4 \mathrm{pm}$ and I have just arrived at Kirsten's apartment. We have made an appointment for a combined shopping, cooking, and eating session. Kirsten tells me right away that she has decided that we are going to make 'Jordskokke-suppe' (soup of Jerusalem artichoke). As she has already bought the Jerusalem artichoke at the green grocers on the way home from school, she explains that we are only going to buy onion and milk at the supermarket along with "some side-dishes, which I have not yet decided". She describes the choice of extras as a choice between bacon and chicken (...). The first shelf she approaches at the supermarket is the bread shelf. She tells me that she finds the bread in this particular store "boring" and that she "never buys it". [We get the onion and milk and she decides on chicken for accompanying the soup] (...). On the way towards the cash register, she stops by a tall mounting of different types of products: Christmas decorations and chocolate but also some bags with 'nan bread'. She briefly glances at one of them and says: "they usually taste fine". She puts the bread in her shopping basket. I ask her if she has tried this type of bread before. She says that she has tried something that looks the same from another supermarket, and that she usually likes the taste of the spices used in it. (Field notes)

Being a normal consumer involves the ability to let oneself be seduced by, and to act spontaneously when faced with, a good offer. The possibility of changing one's mind, of giving in to sudden temptations, of breaking the usual routines when facing new products, and of including elements in the meal other than those planned for were all opportunities that appeared to be highly appreciated 
by the participants who were followed around. We argue that the realisation of such possibilities signals how important it is to experience the liberty to choose freely what to eat. In our data, it appears that disturbances of systematic product display and shopping rhythms often sets the scene for these values of liberty linked to ideas of proper consumption. In the case of the spot market and the Nan bread purchases, the placement of food products broke with the otherwise well-defined, systematic arrangement provided by the design of the supermarket, where products are placed into strict categories and not mixed up.

For Kirsten in the examples above, practising the freedom of consumption did not involve any violation of the dietary regimen in the MUFObes trial. It was different for Laura, who refused to dispense with some of the products supposed to be almost eliminated from her MUFA diet. She bought cheese due to her personal desires, but also in order to take proper care of visitors. Laura also refused to dispense with red meat to the extent required by the MUFA diet. She deliberately planned her cheese and meat purchases ahead of shopping trips. Together with other informants, Laura insisted that her life quality depended on not restricting her eating too much and, especially, not displaying inappropriate self-deprivation when eating with others. She described others who engaged in such self-restrictions as 'hysterical', thereby underlining the value of occasional release. Although insisting that her choice of eating what she desired was the right and 'normal' choice, Laura attempted to solve the contradiction between the dietary restrictions of the Mufobes study, and her choice not to deprive herself of important foods in different ways. She would, for instance, buy the foods she desired, and then impose hard restrictions on her intake of them at home. For example, she put her cheese in a box and observed strict rules regarding daily intake, and she split the red meat up into small portions of $200 \mathrm{~g}$ each, which she then put in her freezer. Further, she ensured that all meals she made with the meat lasted for two days. In this way techniques of self- 
control exercised in spheres outside the supermarket allowed her to purchase more freely inside the supermarket.

\section{Discussion}

In liberal market economies, consumption through the idea of free choice attains a central role in the production and reproduction of our understanding of identity and the individual as an autonomous self. Which types of commodities are important in processes of identity formation varies in time and space and in accordance with the identity-related issues faced by individuals and groups. However, in the present study we argue that food shopping plays a double role in the formation of what is seen as a normal identity by a group of individuals concerned with body weight. Being able to control food consumption is of key importance in the attainment of a normal body, on the one hand. On the other, enacting individual freedom through the willingness to react to desires, to be spontaneous, to seek newness in consumption, and to observe the ethos of thrift, seems to be central to the participants' identity as normal consumers.

The desire for a culturally and medically defined normal body size requires the individual to engage in strict self-controlling acts which may lead to acceptance of forces of external control. But the values and techniques of control drawn upon are opposed by some of the values linked to the practice of freedom and autonomy in the sphere of consumption. When reporting about their engagement in strictly controlled attempts at weight-loss maintenance, participants would talk about how the external control, in the form of energy-balance calculation and surveillance of diet composition, would prevent them from exercising freedom of consumption. Even though techniques of self-control employed in the act of regular shopping were viewed as necessary to obtain the goal of a normal body, strategies were observed that violated the principles of selfcontrol. Instead, these strategies served to allow the shopper to choose spontaneously, to seek 
pleasure in certain foods, and to purchase whatever was best, in terms of quantity and price, thereby fulfilling norms related to consumption.

However, the values of freedom and control did not always contradict one another in such clear-cut ways. The external control of dietary compliance exercised in the MUFObes trial was not only regarded as a restriction. The controlled qualitative limits set for consumption protected the goal of dietary change, and therefore freed the individual participant from personally defining and observing limits necessary for achieving such change. And for the participants who were still overweight, shopping together with other people with similar experiences liberated the participants from social control in ordinary supermarkets. In this way, for many informants in this study, external control was also experienced as consumer liberation. As Lave observes (1988), the architectural structure of ordinary supermarkets and their display of products not only influence the actions of consumers, but also enables consumers to integrate this structure in their own counterstrategies. In a similar manner, design and techniques in regular supermarkets functioned in ways that made the informants experience consumer freedom, but also feel restricted in their consumption. This was the case, for example, when packaging determined the quantities consumers bought or when special offers called for economic rationality at the expense of the observance of dietary principles. Hence the study showed how sources of external control, as well as mechanisms of self-control and self-release, can be experienced both as supportive of and an obstacle to the achievement of normality.

Concepts of tamed and controlled hedonism can be used fruitfully to discuss food shopping among people concerned about their weight, as they draw attention to the role of values of control and freedom. The present analysis shows, however, that the attributed roles of pleasure seeking and self-control in identity formation (Falk 1997; Sassatelli 2009; Campbell 1996) may not adequately cover the consumption practices of the people with weight concerns. For such individuals, not only 
does pleasure seeking need to be tamed, but so does control. The control over food consumption that people with weight concerns typically try to exercise risks violating values of freedom linked to proper consumption. People who are too restricted in their food consumption are regarded as suspicious, and not normal, and hence the occasional submission to pleasure and spontaneity constitutes an important action proving that self-restriction is not out of control.

In Miller's study of shopping (1998), the treat is described as the exception, which serves to prove the centrality of thrift as a value in shopping practices. However, among people with weight concerns it seems that perhaps the meaning of thrift and treat overlap since thrift may legitimise the seeking of personal pleasure and the release from dietary control.

Consumption is related to values other than pleasure and thrift. Consumption and in particular food shopping may be viewed as mundane, everyday practice which is usually performed in an unreflexive and routine manner (Gronow \& Warde, 2001). However, for the people in this study who are concerned with their weight, food shopping in a supermarket deviates somewhat from this description. It is true that, compared to many other consumption situations, food shopping is an activity which needs to be dealt with efficiently at an everyday level. But it is perhaps first and foremost an activity which puts them into direct contact with strongly desired food objects (Nielsen \& Micheelsen 2011). Rather than being a pleasure-less activity, food shopping is viewed as problematic because pleasure is too strongly involved. Consequently, the act of shopping becomes a highly reflexive activity where the conscious breaking of routinised behaviours, such as buying products too high in fat or making too many impulse purchases, is strived for. It should be noted, however, that the participants' engagement in a controlled scientific study may have made their reflexivity more pronounced than that of other weight-concerned individuals.

In line with other studies (Crawford, 1984; Sarlio-Lähteenkorva, 2000), this study suggests that the achievement of 'normal' body does not suffice in defining the experience of normality 
among people concerned about their weight. The study adds to the knowledge about experiences of normality by supplementing with data from the context of food shopping showing that normal weight control behaviour in this context includes seeking pleasure and freeing oneself from restrictions. It has been suggested that the theoretical concept of intersectionality can be used to explain how body size is not the only factor shaping the experience of obesity or overweight (Hopkins 2012). The present study contributes further to our understanding of the experience of living in large bodies by suggesting that, for many people, their identity as a consumer is also important. This is important since previous studies which have included how obese and overweight people approach contexts of food shopping (e.g. Thomas et al. 2008; Lewis et al.2011; Christiansen et al. 2012) have overlooked this element in identity formation, emphasizing only the concern with bodily stigma, obtaining self-control and body normality.

The informants in this study were all healthy individuals who took part in a clinical controlled dietary intervention with a focus on weight control. It is likely that people whose excessive weight has given rise to health problems would be more concerned with self-control than those in this study. This is indicated in some studies focusing on the experiences of obese people (Christiansen et al. 2012; Lewis et al. 2011). As this was a qualitative study, there was no possibility for linking, for example, the concern with self-control to socioeconomic or educational background. Also people who were young, who were students, and/or who lived alone, were overrepresented in the study. It is therefore highly likely that the consumption practices of the study sample reflect these characteristics to some extent, and that the study's analytical scope is limited accordingly. For instance, one study found differences in motivations, in the influence of social relations, and in perceptions of control, between younger and older overweight persons (Robertson et al. 2014). Studies have also identified contrasts between people with different racial characteristics (Ristovski-Slijepcevic et al. 2010), and between men and women (Mallyon et al. 2010), in their 
dieting experiences. Hence a sample of informants with a higher age who are more firmly established, for example, in their jobs, and with their partners and children, would have probably enabled us to also analyse food shopping more as a daily chore in a busy family life, and to investigate how satisfying the needs of others relates to the experience of control and freedom when shopping for food (e.g. see Miller, 1998). But with these reservations, this study suggests that freedom and control are not diametrically opposed, but are values which may represent two equally important ambitions interwoven in complementary and composite ideals of normality for people with weight concerns.

\section{Acknowledgements}

The study was financed by the Danish Research Agency's programme for food and nutrition research (FELFO/2056-03-0016). The group conducting the MUFOBES project (Anette Due, Thomas Meinert Larsen and Arne Astrup) is thanked for generously allowing access to project participants and material. First of all, the informants are thanked for participating in the interview and observation study.

\section{References}

Alasuutari, P. (1995). Researching Culture: Qualitative Method and Cultural Studies. London: Sage.

Au, N.; Marsden, G.; Mortimer, D. and Lorgelly, P.K. (2013). The cost-effectiveness of shopping to a predetermined grocery list to reduce overweight and obesity. Nutrition \& Diabetes, 3, e77

Baudrillard, J. (1998). The Consumer Society. London: Sage. 
Bauman, Z. (2007). Liquid Times: Living in an age of uncertainty. Cambridge: Polity Press.

Bauman, Z. (2003). Frihed [Freedom]. Copenhagen: Hans Reitzels Forlag.

Bauman, Z. (1992). Intimations of postmodernity. New York: Routledge.

Bevelander, K.E.; Anschütz, D.J.; Engels, R.C.M.E. (2011) Social modeling of food purchases at supermarkets in teenage girls. Appetite

Beck, U. (1992). The Risk Society. Towards a New Modernity. London: Sage

Bowlby, R. (1997). Supermarket Futures. In P. Falk \& C. Campbell (eds) The Shopping Experience. London: Sage, pp. 92-110.

Campbell, C. (1996). The Sociology of Consumption. In D. Miller (ed) Acknowledging consumption - a review of new studies. London: Routledge, pp. 96-126.

Chapman, G. E. (1999). From "Dieting" to "Healthy Eating": An Exploration of Shifting Constructions of Eating for Weight Control. In J. Sobal \& D. Maurer (eds) Interpreting Weight. New York: Aldine de Gruyter, pp. 73-89.

Christiansen, B.; Borge, L.; Fagermoen, M.S. (2012). Understanding everyday life of morbidly obese adults-habits and body image. Int J Qual Stud Health Well-being. 2012; 7: 17255

Cordell, G. and Ronai C. R. (1999). Identity Management among Overweight Women. Narrative Resistance to Stigma. In J. Sobal \& D. Maurer (eds) Interpreting Weight. New York: Aldine de Gruyter, pp. 29-47.

Corrigan, P. (1998). Theoretical Approaches to Consumption. In P. Corrigan (ed) The Sociology of Consumption. London: Sage, pp. 17-32. 
Crawford, R. (1984). A cultural account of "health": control, release, and the social body. In J. B. McKinlay (ed) Issues in the political economy of health care. New York: Tavistock Publications, pp. 61-103.

Due AP , Larsen TM , Mu H , Hermansen K, Stender S , Astrup A (2008) . Comparison of 3 ad libitum diets for weight-loss maintenance, risk of cardiovascular disease, and diabetes: a 6-mo randomized, controlled trial. American Journal of Clinical Nutrition; 88(5):1232-1241.

Falk, P. \& Campbell, C. (eds.) (1997). The Shopping Experience. London: Sage.

Falk, P. (1997). The Consuming Body. London: Sage.

Featherstone, M. (2007). Consumer Culture and Postmodernism. London: Sage.

Germov, J. \& Williams, L. (1999). Dieting Women. Self-Surveillance and the Body Panopticon. In J. Sobal \& D. Maurer (eds) Weighty Issues. Fatness and Thinness as Social Problems. New York: Aldine De Gruyter, pp. 117-132.

Giddens, A. (1991). Modernity and Self-Identity: Self and Society in the Late Modern Age. Stanford: Stanford University Press.

Gronow, J. \& Warde, A. (2001). Introduction. In J. Gronow \& A. Warde (eds) Ordinary Consumption. London and New York: Routledge, pp. 1-8.

Hacking, I. (1990). The Taming of Chance. Cambridge: Cambridge University Press.

Hopkins, P. (2012). Everyday Politics of Fat. Antipode, 44: 1227-1246 
Lave, J. (1988). Through the supermarket. In Lave, J. Cognition in practice. Mind, mathematics and culture in everyday life. Cambridge: Cambridge University Press, pp. 145-169

Lehtonen, T-K. \& Mäenpää, P. (1997). Shopping in the East Centre Mall. In P. Falk \& C. Campbell (eds) The Shopping Experience. London: Sage, pp.136-165.

Lewis, S.; Thomas, S.L.; Warwick Blood, R.; Castle, D.; Hyde, J.; Komesaroff, P.A. (2011). How do obese individuals perceive and respond to the different types of obesity stigma that they encounter in their daily lives? A qualitative study. Social Science \& Medicine; 73:1349-1356

Lupton, D. (1998). Food, the Body and the Self. London: Sage.

Mallyon, A.; Holmes, M.; Coveney, J.; Zadoroznyj, M. (2010). I'm not dieting, 'I'm doing it for science': Masculinities and the experience of dieting. Health Sociology Review: Vol. 19, Food, Ethics and Identity, pp. 330-342.

Miller, D. (1998). A Theory of Shopping. Cambridge: Polity Press.

Nielsen, A. \& Micheelsen, A. (2011). Strong Desires and Strategies of Self-control: A Semiotic Approach to Food Cravings. Signs, 4:1- 28.

Papies, E.K.; Potjes, I.; Keesman, M.; Schwinghammer, S. and van Koningsbruggen, G.M. (2014). Using health primes to reduce unhealthy snack purchases among overweight consumers in a grocery store. International Journal of Obesity; 38: 597-602.

Ristovski-Slijepcevic, S; Bell, K.; Chapman, G.E.; Beagan, B.L. (2010). Being 'thick' indicates you are eating, you are healthy and you have an attractive body shape: Perspectives on fatness and food 
choice amongst Black and White men and women in Canada. Health Sociology Review: Vol. 19, Food, Ethics and Identity, pp. 317-329.

Robertson, A.; Mullan, B.; Todd, J. (2014). A qualitative exploration of experiences of overweight young and older adults. An application of the integrated behaviour model. Appetite, 75: 157-164 Research report

Rose, N. (1996). Towards a Critical Sociology of Freedom. Nordiske Udkast; 1: 3-21.

Saarela, A-M. (2013). Change of behaviour when selecting food products in a supermarket environment after reminding consumers about weight management. Public Health Nutrition; 17(5), $1147-1155$.

Sarlio-Lähteenkorva, S. (2000). "The battle is not over after weight loss": stories of successful weight loss maintenance. Health ;4(1): 73-88.

Sassatelli, R. (2001). Tamed hedonism: Choice, desires and deviant pleasures. In J. Gronow \& A. Warde (eds) Ordinary Consumption. London and New York: Routledge, pp. 93-106.

Sassatelli, R (2009). Consumer Culture. History, Theory and Politics. London: Sage.

Slater, D. (1996). Consumer Culture and Modernity. Oxford: Blackwell.

Sobal, J. (1999). The Size Acceptance Movement and the Social Construction of Body Weight. In J. Sobal \& D. Maurer (eds) Weighty Issues. New York: Aldine de Gruyter, pp. 231-250.

Sobal, J. (2004). Sociological Analysis of the Stigmatisation of Obesity. In J. Germow \& L. Williams (eds) A Sociology of Food \& Nutrition: The Social Appetite. 2nd edn, Melbourne: Oxford University Press, pp. 383-402. 
Spradley, J. (1980). Participant Observation. New York: Holt, Rinehardt and Winston.

Stearns, P. (1997). Fat History. New York: New York University Press.

Stinson, K. (2003). Women and dieting culture: inside a commercial weight loss group. Piscataway: Rutgers University Press

Strauss A. \& Corbin J. (1998). Basics of Qualitative Research. Techniques and Procedures for developing Grounded Theory. 2nd ed. Sage Publications: London.

Taylor, C. (2003). Sources of the Self. The Making of the Modern Identity. Cambridge: Cambridge University Press.

Thomas, S (2008). Being "fat" in today's world: a qualitative study of the lived experience of people with obesity in Australia. Health Expectations, 11:321-330

Willett, W. C. (2001). Eat Drink and Be Healthy. The Harvard Medical School Guide to Healthy Eating. New York: Simon \& Schuster Source.

Yuker, H. E. \& Allison, D. B. (1994). Obesity: Sociocultural Perspectives. In D. W. Newman \& B. Capelle (eds) Understanding Eating Disorders: Anorexia Nervosa, Bulimia Nervosa, and Obesity. London: Taylor \& Francis, pp. 243-270. 